\title{
BioLink
}

Jurnal Biologi Lingkungan, Industri, Kesehatan

Available online http://ojs.uma.ac.id/index.php/biolink

\section{CORRELATION BETWEEN ADHERENCE OF ANTIHYPERTENSIVE DRUGS USE AND BLOOD PRESSURE CONTROL IN PATIENTS WITH ESRD UNDERGOING HEMODIALYSIS}

\author{
Tedy Kurniawan Bakri1 ${ }^{*}$, Raihanul Akmal'1, Azizah Vonna1, Lydia Septa \\ Desiyana ${ }^{1}$, Fitrah Sari²
}

1Pharmacy Department, Faculty of Mathematics and Natural Sciences, Universitas Syiah Kuala, Indonesia

2 Faculty of Medicine, Universitas Syiah Kuala, Indonesia

Submited : 22-04-2021; Reviewed :12-06-2021; Accepted : 04-01-2022

*Corresponding author: E-mail : tedvkbakri@unsviah.ac.id

\begin{abstract}
Antihypertensive therapy used in patients with End-Stage Renal Disease undergoing hemodialysis is objected to decrease mortality related to ESRD complications. Nonadherence to antihypertensive therapy can lead to uncontrolled blood pressure. This study aims to determine the level of adherence to antihypertensive drugs and its correlation to blood pressure control in ESRD patients undergoing hemodialysis. It was an observational analytic study based on the cross-sectional method. Sixty person subjects were involved using the quota sampling technique. The level of adherence was examined using the Modified Morisky Scale questionnaire. Blood pressure data were obtained from mean values of respectively pre, during, and post-hemodialysis blood pressure within four hemodialysis visitations. The data was examined bivariately using the Chi-square test with a 95\% confidence interval. The results show most patients have high level of adherence to antihypertensive treatments (55\%) yet have uncontrolled levels of blood pressure (95\%). The Chi-square analysis found there is no significant relationship between the level of adherence to antihypertensive therapy and the average blood pressure level of ESRD patients who undergo hemodialysis ( $p$-value 0,301). This finding suggests a consideration in monitoring the effectivity of hypertension management that adherence is not a single significant factor affecting the successfulness of medication.
\end{abstract}

Keywords: Level of adherence; antihypertensive; blood pressure; ESRD; CKD

How to Cite: Bakri, T.K., Akmal, R., Vonna, A., Desiyana, L.S., \& Sari, F. (2022). Correlation Between Adherence Of Antihypertensive Drugs Use And Blood Pressure Control In Patients With Esrd Undergoing Hemodialysis, BioLink: Jurnal Biologi Lingkungan, Industri dan Kesehatan, Vol. 8 (2): Hal. 229-241 
Bakri, T.K., Akmal, R., Vonna, A., Desiyana, L.S., \& Sari, F. Correlation Between Adherence Of Antihypertensive Drugs Use And Blood Pressure Control In Patients With Esrd Undergoing Hemodialysis

\section{INTRODUCTION}

End-Stage Renal Disease (ESRD) is one of the major global health problems because of its significance in terms of prevalence and socioeconomic burden. ESRD which requires definitive therapy in the form of kidney replacement therapy (kidney transplantation or dialysis therapy) is the final manifestation of the progression of Chronic Kidney Disease (CKD). Based on the Global Burden of Disease Study in 2015, CKD was ranked $19^{\text {th }}$ as the highest cause of death in 2013 and the number of deaths in the world caused by CKD reached 956,200 people (Naghavi et al., 2015).

Indonesia is one of the countries with a fairly high incidence of CKD, even kidney disease care is the second-largest financing provider from BPJS for health, which reached 2.68 trillion rupiahs in 2015 (Kemenkes RI, 2017). The results of the 2018 Basic Health Research (Riskesdas) show that the incidence of CKD in Indonesia in 2013 was $0.2 \%$ and increased in 2018 by $0.38 \%$. Aceh is the province with the second-highest prevalence of $0.4 \%$ after Central Sulawesi at $0.5 \%$ (Riskesdas, 2018).

Hypertension is the main cause of CKD and is closely related to CKD forming a dangerous reciprocal cycle. Chronic hypertension can cause damage to the kidneys and vice versa CKD can also cause hypertension. Data sourced from the 10th Report of the Indonesian Renal Registry shows that $90 \%$ of patients undergoing hemodialysis are CKD patients who have fallen to the ESRD stage. As many as $36 \%$ of CKD patients undergoing hemodialysis are caused by hypertension and 51\% of CKD patients suffer from hypertension as a complication of CKD (PERNEFRI, 2017). Initial data obtained from RSUD $\mathrm{dr}$. Zainoel Abidin Banda Aceh in July to September 2018 found 80\% of ESRD patients undergoing hemodialysis received antihypertensive drug prescriptions.

Intensive blood pressure control is the main treatment strategy to slow the progression of CKD while preventing morbidity and mortality in ESRD patients. Although efforts have been made to significantly increase awareness and treatment of hypertension, there are still $30-60 \%$ of patients who have uncontrolled hypertension. Nonadherence to the use of antihypertensive drugs is the most common cause in patients with uncontrolled blood pressure (Louise et al., 2013). Research conducted at the Cincinnati Veterans Affairs Health Center in the United States showed that $33 \%$ of CKD patients had low adherence to antihypertensive drug use and that 
adherence worsened with a decline in kidney function. The risk of uncontrolled hypertension was $23 \%$ greater in patients with low adherence (KE et al., 2010). Research conducted in German nephrology care showed that $50.7 \%$ of hypertensive patients with CKD had uncontrolled blood pressure (Schneider et al., 2018). Evaluation of the level of adherence to the use of antihypertensive drugs carried out at the Research General Hospital (RSUP) of Hasanuddin University in Makassar showed that generally the level of compliance of CKD patients undergoing hemodialysis was classified as a moderate level of compliance with high knowledge but the low motivation of 37.78\% (Fajriansyah \& Nisa, 2018).

In Aceh Province, there is no study evaluating the level of adherence to antihypertensive drug use in ESRD patients. In fact, it is very necessary to evaluate if the level of adherence of antihypertensive drugs is a significant factor that determines the control of blood pressure, especially in ESRD patients undergoing hemodialysis. Adherence level is frequently assumed as significant factor that influence the successfulness of hypertension theraphy. The finding of this study is aimed to contribute to the assessment system of theraphy effectiveness in ESRD patients undergoing hemodialysis, spesifically for the purpose of their blood pressure control.

\section{MATERIALS AND METHODS}

\section{Tools and Materials}

This study had been ethically approved by Health Research Ethics Committee, Faculty of Medicine, Universitas Syiah Kuala, with the issued Letter Number: 56/EA/FKRSUDZA/2019. In this study, several instruments were used, namely the Modified Morisky Scale (MMS) questionnaire to assess patient compliance in the use of anti hypertensive drugs; the Case Management Adherence Guideline (CMAG) algorithm to examine the data obtained from the MMS questionnaire; and patient blood pressure measurement data obtained through the patient's medical record.

\section{Research Path}

This study is a cross-sectional study conducted at the Hemodialysis Installation and Pharmacy Installation at the dr. Zainoel Abidin Banda Aceh. Data collection was carried out during April 2019 using a sampling technique in the form of quota sampling. During this time we collected all patients undergoing 
Bakri, T.K., Akmal, R., Vonna, A., Desiyana, L.S., \& Sari, F. Correlation Between Adherence Of Antihypertensive Drugs Use And Blood Pressure Control In Patients With Esrd Undergoing Hemodialysis

routine hemodialysis (2 times per week) and included all those who met the inclusion criteria that had been set.

The inclusion criteria in question are:

- Outpatient (regular) at the Dialysis Installation of RSUD dr. Zainoel Abidin Banda Aceh.

- Stage 5 CKD patients undergoing routine hemodialysis (2 times per week for at least 2 months).

- Patients who are taking antihypertensive drugs.

- Patients who complete blood pressure data pre-hemodialysis, intradialytic, and post-hemodialysis.

- The patient over 18 years old.

- Patients who are willing to be respondents.

While the exclusion criteria were patients with Acute Kidney Injury (AKI) stage 3 who underwent routine hemodialysis at the Dialysis Installation of RSUD dr. Zainoel Abidin Banda Aceh. From the sampling process, obtained as many as 60 patients who deserve to be included as samples in this study.

In this study, sociodemographic data of patients were also collected consisting of gender, age, education, occupation, duration of hemodialysis, the presence or absence of comorbidities, the number of types of antihypertensive drugs used so far, and the use or absence of other drugs. which can increase blood pressure. The level of patient compliance was measured using the MMS questionnaire through guided interviews. The results of the questionnaire assessment were then reviewed using the CMAG algorithm. The patient's blood pressure data were obtained from the patient's medical record during hemodialysis. The blood pressure in question is the patient's blood pressure measured by the installation officer for two weeks (four times hemodialysis). Blood pressure taken was pre-, intra-, and post-hemodialysis blood pressure. The results of the determination of blood pressure are divided into 2 categories, namely controlled and uncontrolled blood pressure. Controlled blood pressure when: (1) pre-hemodialysis < 140/90 mmHg; (2) intra-dialysis < 135/85 mmHg; and (3) posthemodialysis 130/80 mmHg. Meanwhile, blood pressure is not controlled if: (1) pre-hemodialysis 140/90 mmHg; (2) intra-dialysis 135/85 mmHg; and (3) post-hemodialysis 130/80 mmHg.

\section{Data analysis}

Sociodemographic data of respondents were analyzed univariately and presented in the form of percentage tables. Data analysis of pre-hemodialysis, intradialytic, and post-hemodialysis blood 
pressure was first tested for normality of the data. If the blood pressure data is normally distributed then it is analyzed using the average value (mean), while the data is not normally distributed then it is analyzed using the median value.

Calculation of blood pressure prehemodialysis, intradialytic, and posthemodialysis divided into systolic and of the respondents can be seen in the diastolic blood pressure. Data on the level following table.

Table 1. Sociodemographic characteristics of respondents $(n=60)$

\begin{tabular}{|c|c|c|}
\hline Variable & Frequency & Percentage \\
\hline \multicolumn{3}{|l|}{ Gender } \\
\hline Male & 36 & 60 \\
\hline Female & 24 & 40 \\
\hline \multicolumn{3}{|l|}{ Age (years) } \\
\hline $26-35$ & 3 & 5 \\
\hline $36-45$ & 14 & 23,33 \\
\hline $46-55$ & 17 & 28,33 \\
\hline $56-65$ & 21 & 35 \\
\hline$>65$ & 5 & 8,33 \\
\hline \multicolumn{3}{|l|}{ Education } \\
\hline Primary & 12 & 20 \\
\hline Secondary & 29 & 48,33 \\
\hline Advanced & 19 & 31,67 \\
\hline \multicolumn{3}{|l|}{ Occupation } \\
\hline Civil-servant & 11 & 18,33 \\
\hline Private & 7 & 11,67 \\
\hline Enterpreneur & 12 & 20 \\
\hline Farmer/ labor & 5 & 8,33 \\
\hline Pensionary & 4 & 6,67 \\
\hline
\end{tabular}




\begin{tabular}{lcc} 
Jobless & 2 & 3,33 \\
Housewife & 19 & 31,67 \\
\hline $\begin{array}{l}\text { Duration } \\
\text { hemodialysis } \\
\leq 8 \text { months } \\
>8 \text { months }\end{array}$ & 9 & 15 \\
\hline $\begin{array}{l}\text { Co-morbid } \\
\text { Present }\end{array}$ & 51 & 85 \\
None & 25 & 41,67 \\
\hline $\begin{array}{l}\text { Antihypertensive } \\
\text { drugs taken }\end{array}$ & 35 & 58,33 \\
Monotherapy & & \\
Combination therapy: & 21 & 35 \\
\hline 2 drugs & 18 & 30 \\
3 drugs & 11 & 18,33 \\
$\geq 4$ drugs & 10 & 16,67 \\
\hline $\begin{array}{l}\text { Other drugs use that possibly contribute to the increasing of blood } \\
\text { pressure } \\
\text { Present }\end{array}$ & 9 & 85 \\
None & 51 & \\
\hline
\end{tabular}

Level of Compliance with Anti- two categories, namely the level of

\section{hypertensive Medication}

Assessment of adherence to the use of antihypertensive drugs in this study was determined based on filling out the MMS questionnaire. Questions from the MMS questionnaire were divided into knowledge and motivation of the patient. The distribution of respondents' answers to each question on the MMS questionnaire can be seen in the following figure. 


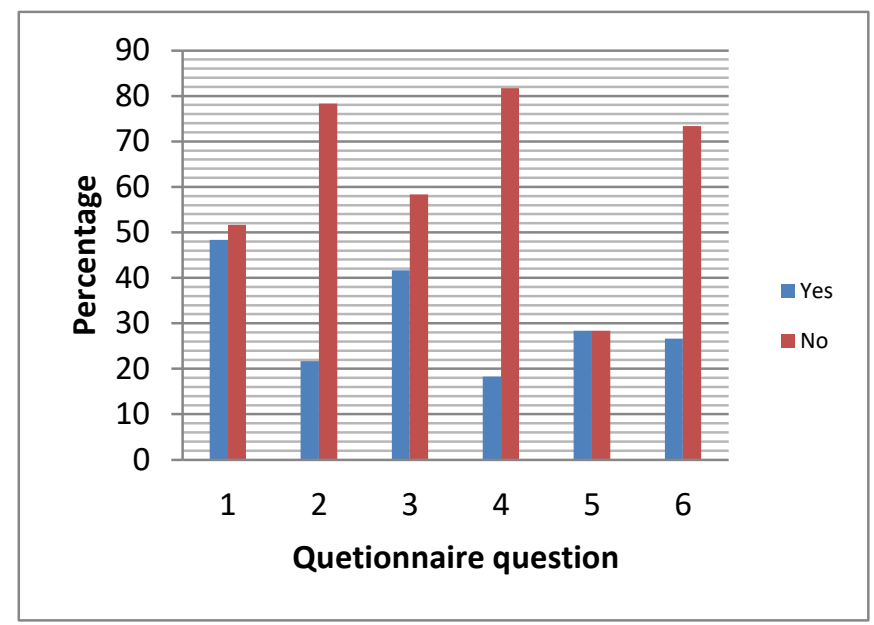

Figure 1. Distribution of respondents' answers to each question on the MMSE questionnaire

Based on Figure 1, the problem found in the category of patient motivation level is that the patient has forgotten to take antihypertensive medication (48.33\%). The problem for the category of knowledge level is that patients have stopped taking antihypertensive drugs if they feel that the patient's body condition is getting better (41.67\%). Most patients try to regularly take antihypertensive drugs (78.33\%), although there are patients who have forgotten to take antihypertensive drugs with a frequency of one or two incidents accidentally due to missed medication time or patients who have stopped taking medication if their body condition getting better, but they realize that their blood pressure will increase if they do not take antihypertensive drugs so that for the next treatment they try to regularly take antihypertensive drugs.
Assessment of adherence to the use of antihypertensive drugs based on high or low levels of patient knowledge and motivation was assessed using the CMAG algorithm which was grouped into 4 quadrants. The four quadrants are quadrant I (low knowledge and low motivation), quadrant II (low knowledge and high motivation), quadrant III (high knowledge and low motivation), and quadrant IV (high knowledge and high motivation). The level of compliance is divided into 3 based on 4 quadrants, namely low level of compliance (quadrant I), moderate level of compliance (quadrant II and III), and high level of compliance (quadrant IV). The description of the level of adherence to the use of antihypertensive drugs in CKD patients undergoing hemodialysis can be seen in Table 2 . 
Table 2. The level of adherence to the use of antihypertensive drugs

\begin{tabular}{cccc}
\hline Quadran & n-Respondent number (\%) & Level of adherence & n-Respondent number (\%) \\
\hline I & $7(11,67)$ & Lower & $7(11,67)$ \\
\hline II & $8(13,33)$ & Moderate & $20(33,33)$ \\
III & $12(20)$ & & \\
\hline IV & $33(55)$ & Higher & $33(55)$ \\
\hline Total & $\mathbf{6 0 ( 1 0 0 )}$ & Total & $\mathbf{6 0 ( 1 0 0 )}$ \\
\hline
\end{tabular}

Based on Table 2, the results show that most of the respondents are at a high level of adherence to using antihypertensive drugs (55\%), namely those who have a high level of knowledge and motivation.

\section{Respondent's Blood Pressure}

Blood pressure data were collected 4 times while patients were undergoing hemodialysis, referring to the study of Agarwal et al., (2008). The respondents underwent routine hemodialysis 2 times a week at the Dialysis Installation of RSUD dr. Zainoel Abidin. The calculation of the blood pressure value in this study uses the average value because the blood pressure value data is normally distributed. Pre and post-hemodialysis blood pressure are said as controlled if their value are $<140 / 90$ $\mathrm{mmHg}$ and $<130 / 80 \mathrm{mmHg}$, respectively. Intra-hemodialysis blood pressure is said as controlled if its value is $<135 / 85 \mathrm{mmHg}$ during the day (Stern et al., 2014).

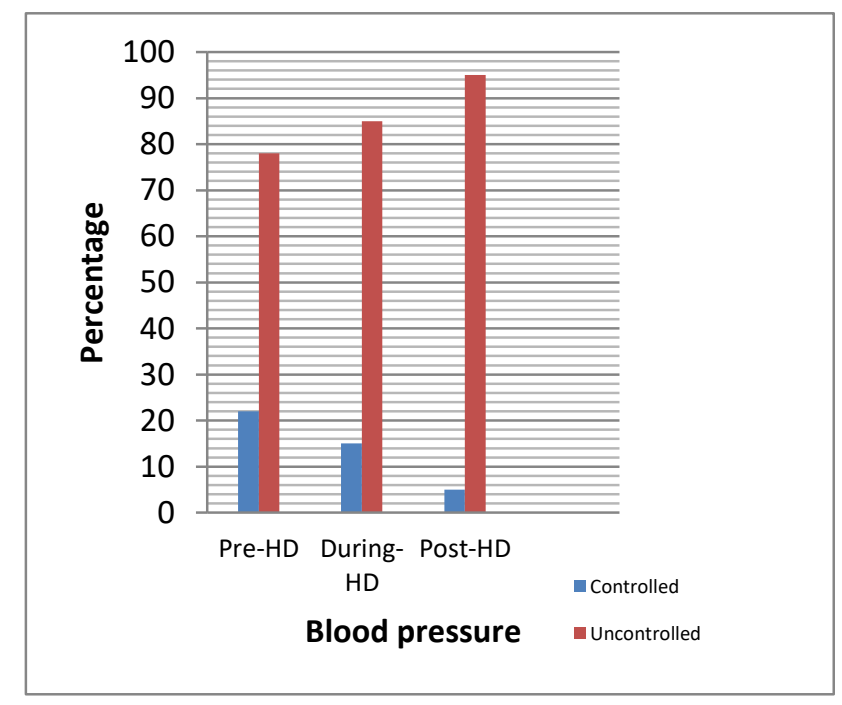

Figure 2. Distribution of patients with controlled and uncontrolled blood pressure based on blood pressure pre, during, and post hemodialysis 
Bakri, T.K., Akmal, R., Vonna, A., Desiyana, L.S., \& Sari, F. Correlation Between Adherence Of Antihypertensive Drugs Use And Blood Pressure Control In Patients With Esrd Undergoing Hemodialysis

Based on Figure 2, the results show that most of the respondents had uncontrolled blood pressure for prehemodialysis (78.33\%), intrahemodialysis (85\%), and posthemodialysis (95\%). Measurement of intra-hemodialysis blood pressure is carried out every hour during the hemodialysis process which lasts 4-5 hours and post-hemodialysis blood pressure measurements are carried out approximately 1 hour after completion of the hemodialysis process. Increased blood pressure that occurs during and after hemodialysis is common in ESRD patients undergoing hemodialysis. This increase in blood pressure is also known as paradoxical hypertension. The increase in blood pressure can be caused by the ultrafiltration process which causes antihypertensive drugs to be eliminated during the hemodialysis process (Malliara, 2007).

The increase in blood pressure that occurs during and after hemodialysis is thought to be due to the elimination of antihypertensive drugs during the hemodialysis process. However, not all antihypertensive drugs can be eliminated during the hemodialysis process. Antihypertensive drugs that can be eliminated during the hemodialysis process are atenolol and nadolol which are classified as -blockers and all antihypertensive drugs that are classified as Angiotensin Converting EnzymeInhibitors (ACE-I) except fosinopril, while antihypertensive drugs are classified as Calcium Channel Blockers (CCB) and Angiotensin Receptor blockers (ARBs) are not eliminated during the hemodialysis process (Georgianos \& Agarwal, 2016). Based on this study, all patients used antihypertensive drugs that were not eliminated during the hemodialysis process. In addition, an increase in blood pressure may occur due to many factors that can cause an increase in cardiac output and vascular resistance in ESRD patients undergoing hemodialysis (Bucharles et al., 2019).

Blood pressure is said as controlled if the average value of each pre, during, and post-hemodialysis blood pressure for 4 times hemodialysis is included in the controlled category and blood pressure is said to be uncontrolled if the average value of each pre-hemodialysis blood pressure, during, and post-hemodialysis for 4 times hemodialysis are included in the uncontrolled category. The description of controlled and uncontrolled blood pressure in CKD patients undergoing hemodialysis can be seen in Table 3 . 
Table 3. Controlled and uncontrolled blood pressure

\begin{tabular}{ccc}
\hline Blood pressure & Frequency & Percentage \\
\hline Controlled & 3 & 5 \\
Uncontrolled & 57 & 95 \\
Total & 60 & 100 \\
\hline
\end{tabular}

Based on Table 3, the results show hemodialysis) so that blood pressure that most of the respondents had measurements become inaccurate uncontrolled blood pressure (95\%) and (Bucharles et al., 2019).

only a few patients had controlled blood pressure (5\%). Limitations of the The relationship between the level of determination of blood pressure may be adherence to the use of antiinfluenced by several factors that affect the measurement results. Factors that can hypertensive drugs and the patient's blood pressure

affect are the white-coat effect, anxiety

The relationship between the level of when inserting the wrong needle into an adherence to the use of antihypertensive arteriovenous fistula, fluctuations in drugs and the blood pressure of ESRD volume status, and limited time for patients undergoing hemodialysis can be relaxation (anxiety when starting seen in Table 4.

Table 4. The relationship between the level of adherence to the use of antihypertensives with the blood pressure of ESRD patients undergoing hemodialysis

\begin{tabular}{lcccc}
\hline \multirow{2}{*}{ Adherence } & \multicolumn{2}{c}{ Blood pressure } & Total & P value \\
\cline { 2 - 3 } & n-Controlled (\%) & n-Uncontrolled (\%) & & \\
\hline Higher & $2(3,33)$ & $31(51,67)$ & $33(55)$ & \\
Moderate & $0(0)$ & $20(33,33)$ & $20(33,33)$ & \multirow{2}{*}{0,301} \\
Lower & $1(1,67)$ & $6(10)$ & $7(11,67)$ & \\
\hline Total & $\mathbf{3 ( 5 )}$ & $\mathbf{5 7 ( 9 5 )}$ & $\mathbf{6 0 ( 1 0 0 )}$ & \\
\hline
\end{tabular}


Bakri, T.K., Akmal, R., Vonna, A., Desiyana, L.S., \& Sari, F. Correlation Between Adherence Of Antihypertensive Drugs Use And Blood Pressure Control In Patients With Esrd Undergoing Hemodialysis

As many as $15 \%$ of respondents from this study used EPO to treat anemia. An increase in blood pressure can be induced by the use of EPO caused by an increase in endothelin-1 concentration, vasoconstrictive response to endothelin-1, an increase in blood viscosity, and peripheral vascular resistance (Sarafidis et al., 2017). This study did not evaluate the use of EPO on the blood pressure of CKD patients undergoing hemodialysis.

The majority of ESRD patients undergoing hemodialysis at the Dialysis Installation of RSUD dr. Zainoel Abidin received $65 \%$ antihypertensive drug combination therapy. The use of combination therapy with antihypertensive drugs is recommended in the Joint National Committee 8 (JNC 8) and European Society of Hypertension and European Society of Cardiology (ESH/ESC) guidelines for patients with systolic pressure above $20 \mathrm{mmHg}$ and diastolic pressure above $10 \mathrm{mmHg}$ or more above the blood pressure target and patients who have a risk of cardiovascular disease in order to achieve the blood pressure target. Although they have received combination therapy with antihypertensive drugs, the majority of ESRD patients undergoing hemodialysis at the Dialysis Installation of RSUD dr. Zainoel Abidin still has uncontrolled blood pressure.
This study did not evaluate the appropriateness of the use of antihypertensive drugs so that it is not known whether the antihypertensive drugs chosen as antihypertensive therapy in the respondents were appropriate or not. The selection of the right antihypertensive drug regimen is very necessary to be able to control the patient's blood pressure by considering during and interdialytic pharmacokinetics, cardioprotective properties, tolerability, and side effects profiles and comorbidities of each patient (Georgianos \& Agarwal, 2016).

Hypertension in ESRD patients undergoing hemodialysis is associated with the risk of cardiovascular disease so that it is not enough just to use antihypertensive drugs, but other drugs are also needed. CKD patients undergoing hemodialysis are generally prescribed other drugs such as phosphate binders, calcimimetics, erythropoiesis stimulants, iron supplements, and other medications to treat the patient's comorbidities (Mechta Nielsen et al., 2018). The use of other drugs is required to manage many of the secondary symptoms of comorbidities in ESRD patients during hemodialysis treatment. This study did not evaluate the appropriateness of the use of other drugs received by the patient. 
Non-pharmacological management of hypertension also needs to be done in ESRD patients undergoing hemodialysis to be able to control blood pressure by limiting salt and fluid consumption. As previously mentioned that excess extracellular fluid (volume overload) in patients can cause an increase in blood pressure. Excessive salt consumption can stimulate osmotic thirst and drinking water causes the body's fluid volume to increase. Therefore, if the restriction of salt consumption is achieved, excess fluid can be minimized (Taniyama, 2016). Based on KDIGO, ESRD patients undergoing hemodialysis should limit salt consumption to less than 5-6 g/day and the increase in fluid volume is monitored based on body weight, i.e. interdialytic weight gain should not exceed $0.8 \mathrm{~kg} /$ day. This study also did not evaluate the restriction of salt and fluid intake in patients (Eknoyan et al., 2013).

There was no relationship between the level of adherence to the use of antihypertensive drugs and the blood pressure of CKD patients undergoing hemodialysis. This is due to the many causes (multifactorial causes) that can cause blood pressure to become uncontrolled such as volume overload, arterial stiffness, endothelial dysfunction, use of EPO, and other causes as well as stress due to feelings of anxiety about hemodialysis which is carried out in the long term and must spend a long time. Time to do regular hemodialysis every week can also trigger an increase in blood pressure. Adherence to the use of antihypertensive drugs certainly cannot be ignored because the use of antihypertensive drugs is necessary in the management of hypertension in CKD patients undergoing hemodialysis and their effective use must be maintained indefinitely to reduce the risk of other cardiovascular disease complications. With the asymptomatic nature of the hypertensive disease and the unlimited duration of treatment, adherence to antihypertensive drug use remains a challenge in patients with this medical condition (Asgedom et al., 2018). Therefore, the role of health workers, especially pharmacists, is needed in intervening in the use of antihypertensive drugs in ESRD patients undergoing hemodialysis.

\section{CONCLUSION}

The majority of ESRD patients undergoing hemodialysis at the Dialysis Installation of RSUD dr. Zainoel Abidin Banda Aceh has a high level of adherence in 
Bakri, T.K., Akmal, R., Vonna, A., Desiyana, L.S., \& Sari, F. Correlation Between Adherence Of Antihypertensive Drugs Use And Blood Pressure Control In Patients With Esrd Undergoing Hemodialysis

using antihypertensive drugs, but no significant relationship was found between the level of adherence to the use of antihypertensive drugs and the control of the patient's blood pressure. This finding should be a consideration in monitoring the effectivity of hypertension management that adherence is not a single significant factor affecting the successfullness of medication. There are a number of other factors that play role in blood pressure control that need to be assessed in patients.

\section{REFERENCES}

Agarwal, R., Metiku, T., Tegegne, G. G., Light, R. P., Bunaye, Z., Bekele, D. M., \& Kelley, K. (2008). Diagnosing Hypertension by Intradialytic Blood Pressure Recordings. Clinical Journal of the American Society of Nephrology, 3(5), 1364-1372. https://doi.org/10.2215/CJN.01510308

Asgedom, S. W., Atey, T. M., \& Desse, T. A. (2018). Antihypertensive medication adherence and associated factors among adult hypertensive patients at Jimma University Specialized Hospital, southwest Ethiopia. BMC Research Notes, 11(1), 27. https://doi.org/10.1186/s13104-018-3139-6

Bucharles, S. G. E., Wallbach, K. K. S., Moraes, T. P. de, \& Pecoits-Filho, R. (2019). Hypertension in patients on dialysis: diagnosis, mechanisms, and management. Brazilian Journal of Nephrology, 41(3), 400-411. https://doi.org/10.159o/2175-8239-jbn-20180155

Eknoyan, G., Lameire, N., Eckardt, K., Kasiske, B., Wheeler, D., Levin, A., Stevens, P. E., Bilous, R. W., Lamb, E. J., \& Coresh, J. (2013). Abstract. Kidney International Supplements, $\quad 3(1), \quad 4$. https://doi.org/10.1038/kisup.2012.76

Fajriansyah, F., \& Nisa, M. (2018). Evaluasi Tingkat Kepatuhan Penggunaan Obat Antihipertensi Pada Pasien Penyakit Ginjal Kronik Lanjut Usia. Jurnal Ilmiah Manuntung, $\quad 3(2)$, 178-185. https://doi.org/10.51352/JIM.V3I2.125
Georgianos, P. I., \& Agarwal, R. (2016). Pharmacotherapy of Hypertension in Chronic Dialysis Patients. Clinical Journal of the American Society of Nephrology, 11(11), 2062-2075. https://doi.org/10.2215/CJN.oo870116

KE, S., CF, E., P, L., LA, S., \& CV, T. (2010). Adherence to antihypertensive agents and blood pressure control in chronic kidney disease. American Journal of Nephrology, $32(6)$, https://doi.org/10.1159/ooo321688

$541-548$.

Kemenkes RI. (2017). Info datin ginjal. Situasi Penyakit Ginjal Kronik, 1-10.

Louise Roy, Brian White-Guay, Dorais, M., Dragomir, A., Lessard, M., \& Perreault, S. (2013). Adherence to antihypertensive agents improves risk reduction of end-stage renal disease. Kidney International, 84(3), 570-577. https://doi.org/10.1038/KI.2013.103

Malliara, M. (2007). The management of hypertension in hemodialysis and CAPD patients. Hippokratia, 11(4), 171-174. http://www.ncbi.nlm.nih.gov/pubmed/1958 2188

Mechta Nielsen, T., Frøjk Juhl, M., FeldtRasmussen, B., \& Thomsen, T. (2018). Adherence to medication in patients with chronic kidney disease: a systematic review of qualitative research. Clinical Kidney Journal, $\quad 11(4), \quad 513-527$. https://doi.org/10.1093/ckj/sfx140

Naghavi, M., Wang, H., Lozano, R., Davis, A., Liang, X., Zhou, M., Vollset, S. E., Abbasoglu Ozgoren, A., Abdalla, S., Abd-Allah, F., Abdel Aziz, M. I., Abera, S. F., Aboyans, V., Abraham, B., Abraham, J. P., Abuabara, K. E., Abubakar, I., Abu-Raddad, L. J., AbuRmeileh, N. M. E., ... Temesgen, A. M. (2015). Global, regional, and national age-sex specific all-cause and cause-specific mortality for 240 causes of death, 1990-2013: a systematic analysis for the Global Burden of Disease Study 2013. The Lancet, 385(9963), 117-171. https://doi.org/10.1016/So1406736(14)61682-2

PERNEFRI, (2017). Program Indonesia Renal Registry. 1oth Report of Indonesian Renal Registry, 1-46.

Riskesdas. (2018). Laporan Riskesdas 2018 Kementrian Kesehatan Republik Indonesia. In Laporan Nasional Riskesdas 2018 (Vol. 53, Issue 9 , pp. 154-165). http://www.yankes.kemkes.go.id/assets/do wnloads/PMK No. 57 Tahun 2013 tentang PTRM.pdf 
Sarafidis, P. A., Persu, A., Agarwal, R., Burnier, M., de Leeuw, P., Ferro, C., Halimi, J.-M., Heine, G., Jadoul, M., Jarraya, F., Kanbay, M., Mallamaci, F., Mark, P. B., Ortiz, A., Parati, G., Pontremoli, R., Rossignol, P., Ruilope, L., Van der Niepen, P., ... Zoccali, C. (2017). Hypertension in dialysis patients. Journal of Hypertension, 35(4), 657-676. https://doi.org/10.1097/HJH.oooooooooooo1 283

Schneider, M. P., Hilgers, K. F., Schmid, M., Hübner, S., Nadal, J., Seitz, D., Busch, M., Haller, H., Köttgen, A., Kronenberg, F., BaidAgrawal, S., Schlieper, G., Schultheiss, U., Sitter, T., Sommerer, C., Titze, S., Meiselbach, H., Wanner, C., Eckardt, K.-U., \& Investigators, for the G. S. (2018). Blood pressure control in chronic kidney disease: A cross-sectional analysis from the German Chronic Kidney Disease (GCKD) study. PLOS ONE, 13(8), e0202604. https://doi.org/10.1371/JOURNAL.PONE.020 2604

Stern, A., Sachdeva, S., Kapoor, R., Singh, J., \& Sachdeva, S. (2014). High Blood Pressure in ialysis Patients: Cause, Pathophysiology, Influence on Morbidity, Mortality and Management. Journal of Clinical And Diagnostic Research, 8(6), MEo1. https://doi.org/10.786o/JCDR/2014/8253.44 71

Taniyama, Y. (2016). Management of hypertension for patients undergoing dialysis therapy. Renal Replacement Therapy, 2(1), 21. https://doi.org/10.1186/s41100-016-0034 